\title{
Increase in meat productivity of young cattle and horses when using environmentally friendly feed additives
}

\author{
Anna Volostnova ${ }^{1, *}$, Alexey Yakimov ${ }^{2}$, and Oleg Yakimov ${ }^{3}$ \\ ${ }^{1}$ Kazan National Research Technological University, 420015 Kazan, Russia \\ ${ }^{2}$ LLC "Research Center for Feed Additives", 420097 Kazan, Russia \\ ${ }^{3}$ Kazan State Academy of Veterinary Medicine named after N.E. Bauman, 420029 Kazan, Russia
}

\begin{abstract}
The article presents the outcomes of studies confirming the feasibility of using zeolitecontaining additives with the objective to optimize the diet of young cattle and horses by the content of minerals in it in order to increase their meat productivity. The research has been conducted in the Republic of Tatarstan. Laboratory studies have confirmed that in terms of hazard the zeolite-containing feed additive belongs to the fourth class of chemicals, specifically, low-toxic compounds in accordance with the requirements of State Standard 12.1.007.76. Scientific and economic experiments have established that the use of a zeolite-containing additive in the diets of young cattle and horses during a store period contributed to an increase in their average daily growth by 10.8 and $12.0 \%$ and slaughter weight by 7.4 and $6.3 \%$ $(\mathrm{p}<0.05)$. The slaughter yield in animals of the experimental groups was 54.0 and $58.9 \%$. The profitability of beef and horse meat production was 17.4 and $19.3 \%$ respectively.
\end{abstract}

\section{Introduction}

One of the most significant issue in present-day conditions is to provide the population with domestic quality livestock products. Thus, the main objective of animal agriculture is to eliminate food shortages through the development and intensification of animal agriculture. It is stipulated by the fact that the consumption of livestock products is one of the most important indicators of people's nutrition quality $[1,2]$.

Cattle meat is the most popular type of meat in Russia. Traditionally high nutritional value, universal consumer qualities and availability of production make beef a very significant component of nutrition in Russia. Compared to meat from animals of other species, beef is characterized by a more favorable ratio of protein and fat. Additionally, it has less cholesterol than lamb and pork. However, its major advantage is that cattle are able to use rough and succulent feed with significantly lower consumption of expensive concentrated feed (30-35\% in the diet) $[3,4]$.

The development of horse breeding for meat production in solving the problem of manufacturing environmentally friendly products including the ones for children and dietetic nutrition is of current importance. Unlike the meat of other animals horse meat contains low cholesterol, which is one of the factors determining its dietary value. This fact is explained by the increase in demand for unique horse breeding products observed in recent years $[5,6]$.

Animals' feeding has a great influence on the meat productivity. Defective feeding is the main reason for the decrease in productivity and efficiency of animal agriculture [2]. Therefore, the use of high-quality feeds and environmentally friendly feed additives is of great importance for the further increase in manufacturing environmentally friendly livestock products.

It is impossible to solve the problem of balanced animal feeding without taking into account the zonal biogeochemical and climatic features of the region while the mineral composition of the feed is subject to significant fluctuations and depends on the type of soil, weather conditions, plant species, vegetation phase, agrochemical measures, harvesting technology, storage and preparation of stuff for feeding [7, 8].

The methods aimed to improve feeding systems by means of various feed additives being metabolic regulators that increase feed efficiency are widely used against the background of a decrease in the feed rations' usefulness caused by economic and environmental reasons under the conditions of increased technogenic intoxication and intensive industrial technology [9-12].

Moreover, feed additives enable to get an additional gain of live weight and reduce animals' mortality without using expensive and time-consuming technologies, thus increasing the profitability of livestock production [13].

The Government of the Russian Federation provides domestic producers with state support with regards to new generation feed additives for farm animals in the context of import substitution. Great attention is paid to environmentally friendly additives based on natural minerals. They contribute to the improvement of animals' digestion and assimilation of nutrients, which

* Corresponding author: volostnova.anna@mail.ru 
provides increased resistance and productivity of animals [14-18].

Currently, organic agricultural products manufactured in certain areas of agricultural industry from raw materials of plant and animal origin, which are grown, produced, processed, certified, labeled, stored and marketed according to the rules of organic production, are of particular demand, have biologically valuable qualities and health-improving properties, and are intended for being consumed by the population in a processed and non-processed form. However, not all Russian citizens can afford eco-products. According to the National Organic Union, only $2 \%$ of Russia's population can currently purchase food under the brands of organic product and biobased product [19].

In accordance with the abovementioned, the development and implementation of effective methods for the production of organic products is of great scientific and practical interest due to the fact that they will expand the market for environmentally friendly products and make it more accessible to consumers.

\section{Materials and methods}

Mineral zeolite-containing feed additive is made on the basis of natural zeolite of the Tatar-Shatrashansky deposit of the Republic of Tatarstan. The mineral composition of the zeolites of this deposit is as follows: clinoptilolite 20.0-30.0 \%; montmorillonite 20.0-30.0 \%; opal cristobalite $28.0-36.7 \%$; calcite $10.6-21.0 \%$; quartz 4.6-11.3\%. The chemical composition is represented by $\mathrm{SiO}_{2}-65.9 \% ; \mathrm{TiO}_{2}-0.35 \% ; \mathrm{Al}_{2} \mathrm{O}_{3}-6.2 \% ; \mathrm{Fe}_{2} \mathrm{O}_{3}$ total - $2.7 \%$; $\mathrm{MnO}<0.01 \%$; $\mathrm{CaO}-17.2 \%$; $\mathrm{MgO}-$ $1.5 \% ; \mathrm{Na}_{2} \mathrm{O}-0.2 \% ; \mathrm{K}_{2} \mathrm{O}-1.4 \% ; \mathrm{P}_{2} \mathrm{O}_{5}-0.1 \%$; p.p.m. $-4.6 \%$.

A toxicological assessment of zeolite-containing feed additive was carried out at the Federal Center for the Toxicological and Radiation Safety of Animals (Kazan) as part of a joint collaboration with the head of the Department of Toxicology, Doctor of Biological Sciences, Professor M.Ya. Tremasov.

Scientific and economic experiments were carried out on the basis of Holding Company "Ak Bars" of the Republic of Tatarstan on black-and-white bulls during the period from 12 to 16 months and foals of the Russian heavy draft from 12 to 18 months. Guided by the principle of analogues, they formed two groups of clinically healthy calf bullo and foals [20]. The diets were based on detailed feeding norms [21]. The conditions of keeping and feeding foals during the test period corresponded to the requirements of State Standard R 56508-2015. Farm-produced feed accounted for more than $50 \%$ of the diet. Rough feed accounted for at least $60 \%$ of the daily diet of foals.

Animals of the control group received the basic diet adopted on the farm. Animals of the experimental group received mineral zeolite-containing feed additive in a dose of $3 \%$ of the dry matter of the diet in addition to the basic diet. During the period of scientific and economic experiments, animals were kept under identical conditions in open feedlots.
The animals' growth was controlled by monthly individual weighing before their morning feeding. Thus, it was noted that the average daily and absolute gain of live weight and relative growth rate were determined. The relative growth of animals for the period of the experiment was calculated by the method of S. Brody.

A control slaughter of animals aged 16 and 18 months was carried out with the objective to study the feed additives impact on meat productivity formation.

Veterinary-sanitary inspection of carcasses was carried out in accordance with the "Rules of veterinary inspection of slaughtered animals and veterinary-sanitary examination of meat and meat products."

The meat obtained from young cattle and horses was evaluated in accordance with the requirements of State Standard 7269-2015 "Meat. Specimen selection methods and organoleptic methods for determining freshness."

Evaluation of economic indicators of animal feeding was carried out by calculating the cost of live weight growth as well as the revenue from sales and profitability of production.

The obtained digital data were processed by the method of variation statistics for the reliability of the difference between the compared indicators with the application of the Student criterion using the Microsoft Excel software package.

\section{Results}

Laboratory studies have confirmed that in terms of hazard the mineral zeolite-containing feed additive belongs to the fourth class of chemicals, specifically, to low-toxic compounds, in accordance with the requirements of State Standard 12.1.007.76.

Acute oral toxicity, irritating effects on the skin and conjunctiva, cumulative properties of the drug, violations of the clinical status and internal organs pathologies were not noted while metabolism activation was noted during toxicological evaluation of mineral zeolitecontaining feed additives, biological testing as well as structural and functional studies in white mice and rabbits.

The main criterion for the growth and development of animals characterizing their intravital meat productivity is live weight. It was found in the course of scientific and economic experiments that the use of mineral zeolite-containing feed additives in the diet contributed to an increase in young cattle and horses' growth.

The first scientific and economic experience showed that feeding with a mineral supplement in the diet contributed to an increase in young cattle growth (Table 1).

Calf bulls of the experimental group gained the largest live weight during the feeding period. Specifically, at the age of 16 months, the bulls of the experimental group put on $19.6 \mathrm{~kg}$ or $4.7 \%$ ( $\mathrm{p}<0.01$ ), which significantly exceeded the live weight of the bulls in the control group. The average daily increase in bulls during the feeding period in the experimental group was $101.7 \mathrm{~g}$ or $10.8 \%$ more $(\mathrm{p}<0.05)$ than the bulls in the 
control group. The change in the average daily gain of the calves during the feeding period is shown in Fig. 1. The indicator of the absolute increase in live weight in the experimental group was $13.4 \mathrm{~kg}$ more $(\mathrm{p}<0.05)$, while the relative growth rate increased by $7.9 \%$.

Post-slaughter studies and veterinary-sanitary examination of carcasses and internal organs of calf bulls in the control and experimental groups were carried out, visual pathological changes were not detected, and their satisfactory bleeding was noted. The carcasses were similar in appearance and degree of bleeding. No visible differences between the groups were observed. Assessment of the internal organs condition was carried out by appearance, surface integrity and color. On examination, it was found that the internal organs were without damage, hemorrhage and neoplasms, proportional in size and had a color characteristic of each organ.

Table 1. Zootechnical indicators during calf bulls store feeding (on a per 1 head basis)

\begin{tabular}{|l|c|c|}
\hline \multirow{2}{*}{\multicolumn{1}{|c|}{ Indicator }} & \multicolumn{2}{|c|}{ Group } \\
\cline { 2 - 3 } & control & experimental \\
\hline Live weight, kg: & $303.2 \pm 4.6$ & $309.4 \pm 4.8$ \\
12 months & $359.4 \pm 3.2$ & $370.1 \pm 3.7 *$ \\
14 months & $417.3 \pm 4.6$ & $436.9 \pm 5.1 * *$ \\
16 months & & \\
\hline Weight gain: & $114.1 \pm 4.1$ & $127.5 \pm 4.4^{*}$ \\
absolute, kg & $943.1 \pm 30.2$ & $1044.8 \pm 33.5^{*}$ \\
daily average, g & 31.7 & 34.2 \\
relative increase, \% & \multicolumn{2}{|}{} \\
\hline
\end{tabular}

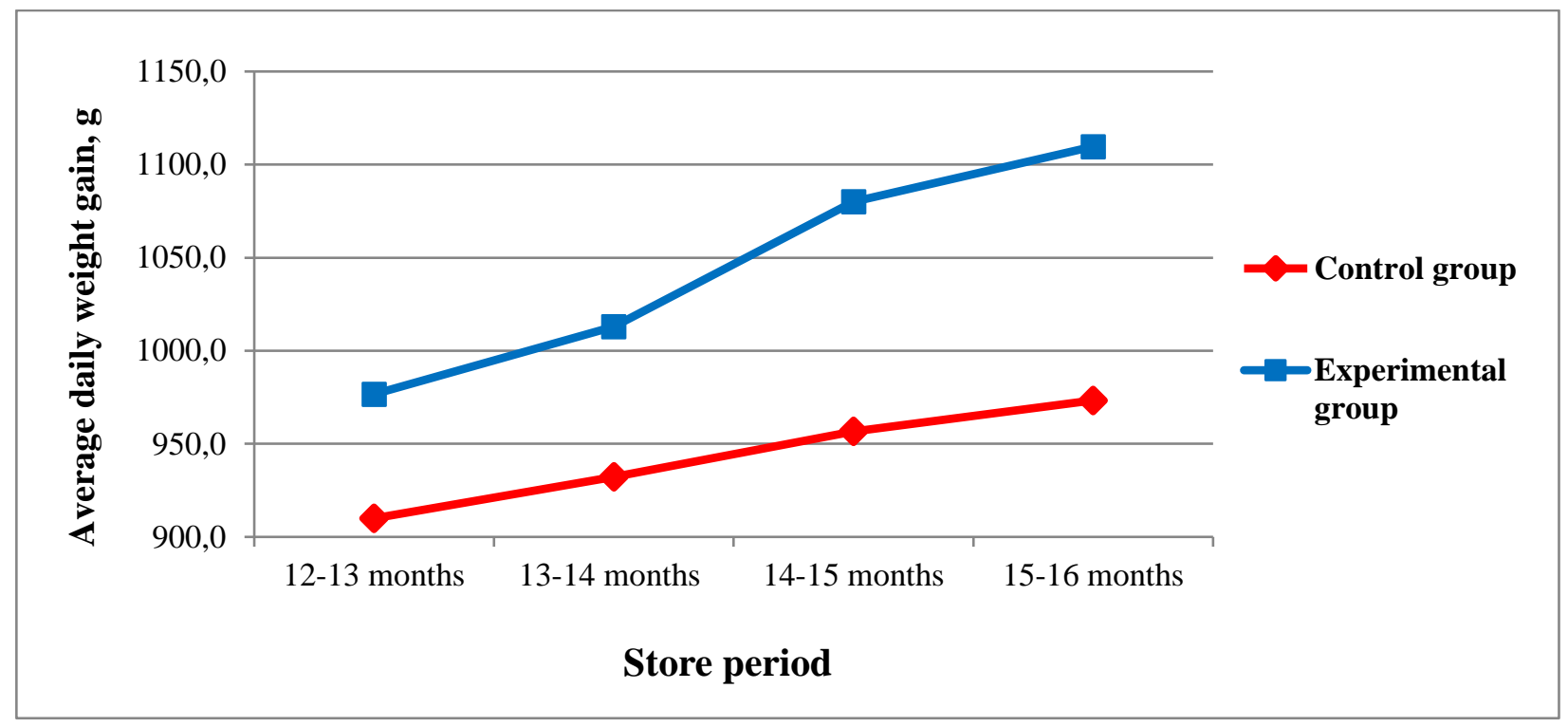

Fig. 1. Dynamics of the average daily gain of calves during the feeding period

According to the organoleptic characteristics, the carcasses of calf bulls in the control and experimental groups did not have visual differences. The crust of drying was pale red, meat was dense and elastic, color and smell were inherent in fresh beef. When assessing the state of fat, it was noted that it had no extraneous odors, was white, had a dense consistency, and crumbled when crushed. The surface of the joints was smooth, shiny, tendons were elastic and dense.

The results of the control slaughter showed that the heavier carcasses were obtained from the bulls of the experimental group, their slaughter mass significantly exceeded the control by $7.4 \%(\mathrm{p}<0.05)$ (Table 2$)$.

Table 2. Results of control slaughter of bulls, on a per 1 head basis

\begin{tabular}{|l|c|c|}
\hline \multirow{2}{*}{ Indicator } & \multicolumn{2}{|c|}{ Group } \\
\cline { 2 - 3 } & control & experimental \\
\hline Pre-slaughter live weight, $\mathrm{kg}$ & $404.5 \pm 6.7$ & $425.8 \pm 5.9^{*}$ \\
\hline Weight of carcass, kg & $214.0 \pm 5.3$ & $229.9 \pm 4.8^{*}$ \\
\hline Slaughter yield, \% & 52.9 & 54.0 \\
\hline
\end{tabular}

At the same time, the slaughter yield in the bulls of the experimental group was $54.0 \%$, while this indicator was equal to $52.9 \%$ in the control group.
Beef production was economically viable in the conditions of scientific and economic experience. Thus, the profitability in the control group was $12.7 \%$ and in the experimental group it was $17.4 \%$.

According to the results of the second scientific and economic experience, the foals of the experimental group were superior in live weight to their peers of the control group (Table 3).

Table 3. Zootechnical indicators during foals store feeding (an a per 1 head basis)

\begin{tabular}{|l|c|c|}
\hline \multicolumn{1}{|c|}{ Indicator } & \multicolumn{2}{|c|}{ Group } \\
\cline { 2 - 3 } & control & experimental \\
\hline Live weight, kg: & $389.6 \pm 4.9$ & $394.1 \pm 5.1$ \\
12 months & $454.8 \pm 4.5$ & $467.2 \pm 4.0^{*}$ \\
15 months & $523.9 \pm 5.3$ & $544.5 \pm 4.7 * *$ \\
18 months & & \\
\hline Weight gain: & $134.3 \pm 5.2 *$ & $150.4 \pm 4.6^{*}$ \\
absolute, kg & $746.1 \pm 29.7 *$ & $835.6 \pm 25.1^{*}$ \\
daily average, g & 29.4 & 32.0 \\
relative increase, \% & \multicolumn{2}{|}{} \\
\hline
\end{tabular}

Thus, the average live weight over the growing periods was greater in animals of the experimental group and by 18 months of age it was $544.5 \mathrm{~kg}$, which significantly exceeds the control group by $20.6 \mathrm{~kg}$ 
$(\mathrm{p}<0.05)$. The absolute increase in live weight of young horses over the period from 12 to 18 months in the control group amounted to $134.3 \mathrm{~kg}$, in the experimental group to $150.4 \mathrm{~kg}$, an average daily gain was respectively equal to $746.1 \mathrm{~g}$ and $835.6 \mathrm{~g}$, which is
$12.0 \%(\mathrm{p}<0.05)$. The relative increase in live weight of foals in the experimental group was $8.8 \%$ more. The dynamics of the average daily growth of foals is shown in Figure 2.

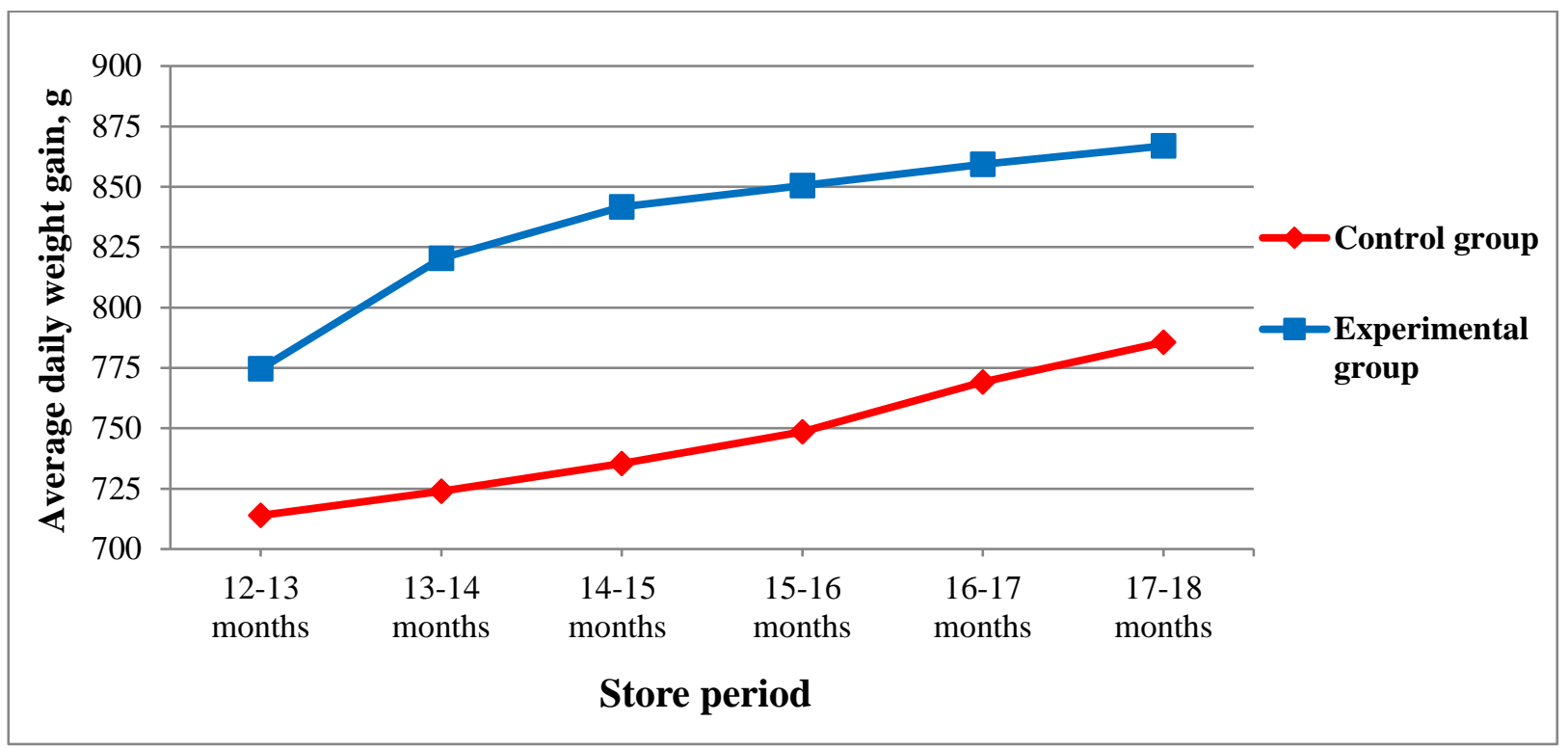

Fig. 2. Dynamics of the average daily gain of foals during the feeding period

Visual pathological changes in the carcasses and internal organs of foals in the control and experimental groups were not detected during the veterinary and sanitary examination. It was established that the internal organs were without damage, hemorrhage and neoplasms, were proportional in size and had a specific color for each organ. Visually, the carcasses of the animals in the experimental group did not differ from the control ones; they had a dark red crust of drying, the muscles on a cut were slightly moist and did not leave a wet spot on the filter paper, the meat consistency was dense, elastic, the color and smell of meat were specific to fresh horse meat. The fat was yellowish in color, had no odors and a dense consistency. The tendons were elastic and dense; the surface of the joints was smooth and shiny.

On the whole, horses are not inferior to meat breeds of cattle in terms of meat productivity. According to the results of the control slaughter, it was found that the use of mineral zeolite-containing feed additives in the diets of young horses had a positive effect on their meat productivity (Table 4).

Table 4. Results of control slaughter of foals, on a per 1 head basis

\begin{tabular}{|l|c|c|}
\hline \multirow{2}{*}{ Indicator } & \multicolumn{2}{|c|}{ Group } \\
\cline { 2 - 3 } & control & experimental \\
\hline Pre-slaughter live weight, $\mathrm{kg}$ & $507.4 \pm 5.3$ & $527.6 \pm 4.5^{* *}$ \\
\hline Weight of carcass, kg & $292.3 \pm 4.9$ & $310.8 \pm 4.3^{*}$ \\
\hline Slaughter yield, \% & 57.6 & 58.9 \\
\hline
\end{tabular}

It was found that the carcasses mass was $18.5 \mathrm{~kg}$ or $6.3 \%$ more in the experimental group ( $\mathrm{p}<0.05)$. At the same time, the slaughter yield increased by $2.3 \%$ and amounted to $58.9 \%$.
Foals' store feeding was economically justified in the conditions of scientific and economic experience. Thus, the profitability of horse meat production in the control group was $13.5 \%$, and in the experimental group it was equal to $19.3 \%$. The $5.8 \%$ increase in profitability in the experimental group was due to the large absolute increase in the foals and the additional profit was received when selling on a per head basis.

\section{Conclusion}

The research has shown that the use of mineral zeolitecontaining feed additives in the diet enabled to increase:

- average daily live weight gain of young cattle and horses by 10.8 and $12.0 \%$;

- slaughter mass of calf bulls and horse foals by 7.4 and $6.3 \%$, with a slaughter yield of 54.0 and $58.9 \%$, respectively;

- profitability of beef and horse meat production by 4.7 and $5.8 \%$ respectively.

The use of mineral zeolite-containing additives in feeding bulls and foals pose no negative affect on the veterinary and sanitary indicators of beef and horse meat. Organoleptic indicators met the requirements of State Standard 7269-2015 for fresh meat.

The results obtained enable to assess the prospect of using mineral zeolite-containing feed additives in the feeding of young cattle and horses in order to increase meat productivity and profitability of meat production.

\section{References}


1. G.Ya. Safiullina, M.S. Ezhkova, G.O. Ezhkova, Sci. notes of the Kazan State Acad. of Veter. Med. named after N.E. Bauman, 222(2), 198-201 (2015)

2. A.T. Mysik, Zootech., 1, 2-5 (2015)

3. N.P. Sudarev, T.N. Schukina, V.A. Burmistrov, V.S. Leontiev, R.P. Linkevich, V.V. Asyanin, Agrar. Review, 3, 36-40 (2013)

4. T.N. Schukina, N.P. Sudarev, Young Scientist, 8, 71-74 (2015)

5. M.A. Kretov, A.V. Ustinova et al., Storage and process. of agricult. raw mater., 2, 32-33 (2005)

6. V.S. Koveshnikov, Horse breed. and equestr. Sports, 5, 4-5 (2013)

7. A.V. Yakimov, R.Sh. Kayumov, V.V. Gromakov, Modern probl. of sci. and ed., 1 (2014)

8. L.P. Zaripova, M.G. Nurtdinov, N.N. Khazipov et al., Feed of the Republic of Tatarstan: composition, nutrition and use (Kazan, 2010)

9. A.A. Gaidash A.A., Experim. Stud., 1(53), 115-122 (2016)

10. V.A. Alekseev, E.Yu. Nemtseva, Bull. of the Ulyanovsk State Agricult. Acad.: sci. and theoret. J., 3(39), 105-108 (2017)

11. M. Safaeikatouli, Y. Jafariahangari, A. Baharlouei, Pakistan J. of Nutrit., 3, 233-237 (2011)
12. H. Nassiri Moghaddam, R. Jahanian, H. Jahanian Najafabadi, M.M. Madaeni, J. of Biolog. Sci., 8(2), 328-334 (2008)

13. V.Ya. Ponomarev, E.Sh. Yunusov, G.O. Ezhkova, Bull. of Kazan Technolog. Univer., 15(23), 213-216 (2014)

14. K.Kh. Papunidi, A.V. Ivanov, M.G. Zukhrabov, Veterinar., 1, 62-65 (2000)

15. E.V. Christaki, P.C. Florou-Paneri, P.D. Fortomaris, A.S. Tserveni-Gousi, A.L. Yannakopoulos, Arch. Geflügelk, 70(3), 106-111 (2006)

16. E.Yu. Tarasova, V.P. Korosteleva, V.Ya. Ponomarev, Bull. of Kazan Technolog. Univer., 15(21), 121-122 (2012)

17. O.A. Yakimov, M.K Gainullina, G.A. Gasimova, A.N. Volostnova, G.S Frolov, A.Sh. Salyakhov, M.S. Ezhkova, RJPBCS, 9(6), 1122-1129 (2018)

18. A.M. Ezhkova, A.Kh. Yapparov, V.O. Ezhkov, L.M.-Kh. Bikkinina, I.A. Yapparov, A.P. Gerasimov, Doklady Biolog. Sci., 467(1), 65-67 (2016)

19. I.M. Donnik, B.A. Voronin, Agrar. Bull. of the Urals, 5(147), 101-107 (2016)

20. A.I. Ovsyannikov, Fundamentals of experimental work in animal husbandry (Moscow, 1976)

21. A.P. Kalashnikov, V.V. Scheglov, N.G. Pervov, Norms and diets for feeding farm animals (Moscow, 2003) 